\title{
Proactive solutions to academic dishonesty
}

\author{
Susan B. Thornock \\ Weber State University, Ogden, USA \\ Email: sthornock@weber.edu \\ Received 9 October 2013; revised 12 November 2013; accepted 24 November 2013 \\ Copyright (C) 2013 Susan B. Thornock. This is an open access article distributed under the Creative Commons Attribution License, \\ which permits unrestricted use, distribution, and reproduction in any medium, provided the original work is properly cited.
}

\begin{abstract}
One of the significant individualities of web-enhanced education is the lack of face-to-face interaction between the student and the educator. A consideration in web-enhanced education which has the probability for ethical concern related to the physical disconnection of instructor and learner is the increased potential for academic dishonesty. This can present a dilemma for nurse educators involved in teaching a difficult curriculum, while it can be motivated to improve the quality and student outcomes related to safe patient-centered care. The most blatant consideration in this setting is plagiarism. This article reviews the various facets of this ethical issue and suggests proactive solutions for faculty and administration to deter academic dishonesty.
\end{abstract}

Keywords: Academic Dishonesty; Plagiarism; Web-Enhanced; Safe Patient-Centered Care; Proactive Solutions

\section{PROACTIVE SOLUTIONS TO ACADEMIC DISHONESTY}

Ethics surrounding academic integrity and honesty in education is not a new topic. It has been around for many years and has consistently presented a problem for educators to discern and overcome. Most recently, there have been new challenges to add to the mix and these challenges have had a rapid growth which parallels the growth of the World Wide Web. Identifying and combating plagiarism in Web-enhanced education is a growing cause of concern for educators and administrators alike. Research verifies that an increasing number of university students cheat during the course of their studies, and they have been doing so since high school [1-4]. University students brave enough to participate in plagiarism cause a problem for educators, administrators, and accordingly to the outcome of their own education [5].

\section{SAFETY IN NURSING EDUCATION}

As nursing education is advancing the use of technology in both the clinical simulation environment and the didactic courses, plagiarism has the potential to raise its ugly head causing problems with safe patient care outcomes that are so vital to the nursing profession. Webenhanced education is gaining momentum in nursing, but at the same time comes with legitimate concerns for maintaining quality and safety outcomes [6]. In spite of the difficult curriculum, the ultimate goal of the nurse educator is to prepare the student to achieve program outcomes and become a safe and effective caregiver of our vulnerable healthcare population [7]. Considering the difficulty of the nursing curriculum, and a constant push directed at nurse educators, to improve the quality and student outcomes related to safe patient-centered care [6, 8], web-enhanced teaching strategies that decrease faceto-face contact, and increase asynchronous communication could potentially create a problem for the nursing student and the nursing profession [7].

The Internet, with its abundant and easily accessed information is everywhere and can be compared to a vast territory offered up for free [9]. Because it is so readily available, and so immense, some students might find themselves in trouble if they do not know how to determine fair use of what is found in this massive open space of unlimited information. Apprehension for using alternate teaching-learning methods in nursing may arise when one considers the inherent difficulty of nursing education $[6,10,11]$, the need to respond to a continuously changing health care environment, and the need to ensure safe and effective patient care [6]. It is not unlikely that educators perceive plagiarism as the evil lurking behind computer screen, but there are guidelines for educators and administrators that can decrease that risk.

Students cheat in ways that sometimes boggle the mind of the educator. It is more than just "cutting and pasting” information from the Web. Student's easy ac- 
cess to online resources allow for a great deal of downloadable material for those that are prone to cheat [12]. The internet is easy to use, and the definitions, topics, and terms are easy to search and quick to produce results. The internet has made it easier [13] and plagiarism has become a common occurrence that frequently goes unnoticed by the educator. The need for increased awareness by the institution and the educator are essential and indicate this awareness should lead to action. A priority, in the university setting, is educating the student on what plagiarism entails [13].

\section{PLAGIARISM}

Plagiarism is defined as using others work or words without sitting the source or giving credit to the author of the ideas [13-15]. Plagiarism is the most common type of offence in academic research writing [13]. When it is done by a student it is usually done because the website facilitates it, or because there is pressure from family or peers to achieve in the academic setting. It is also a growing practice because students suffer few consequences and reap the rewards of better grades and more free time. However, while these reasons are fairly high on the list, several experts point out there is also a factor of ignorance that may play a prominent role $[12,14,16]$.

Regardless of the reason a student may cheat or plagiarize, the reality is they do. Furthermore, research indicates it is on the rise and has the potential to continue to increase with the unlimited resources the internet has to offer. Plagiarism may not be obliterated in its totality, but with additional knowledge and awareness, with updated and specific policies, and with an identified pedagogy this concern can be addressed in a manner that will help the student, the educator and the university minimize cheating.

Over $90 \%$ of students and educators are involved or have been involved in at least one, and often more than one, act of dishonesty [4]. Students admitted to cheating in their present studies and educators admitted to cheating in their previous studies. Austin, Simpson and Reynen, completed a study in 2005 on academic honesty and moral development in students taking classes in health professions, which is often synonymous with a difficult curriculum. The first few words of the title for that study emphasized one of the proposed viewpoints of the faculty dealing with plagiarism on a daily bases in the university setting. It stated "The Fault Lies Not in Our Students, but in Ourselves” (p. 143). This title indicated educators and administrators can do something about cheating.

The results of this study also hold up to more recent studies that plagiarism, and dishonest behavior in higher education, especially in Web-enhanced education, are becoming a major problem for most educators, and for most, if not all, schools and universities [12,14,16,17] indicating plagiarism is of epidemic proportions and is both an indicator and rootcause of deteriorating academic standards. This can be especially daunting to nurse educators dealing with a curriculum driven by quality and safety outcomes [6]. With information such as this it becomes a bit daunting for a single educator to tackle this problem on their own. Educators and administration each play a fundamental role, albeit a slightly different role, in understanding and addressing the issue of academic honest and plagiarism in distance education. Both have a responsibility in the detection and prevention of academic dishonesty.

\section{PREVENTION TECHNIQUES- ADMINISTRATION}

In order to begin prevention techniques there is a need for institutions of higher learning to approach plagiarism from the perspective that it does exist, not that it might exist [16]. With this in mind Bretag and Mahmud (2009) stated the administration can then focus on "the three D's: deterring, detecting and dealing with it fairly” (p. 5). These three "D's" indicate administration has the overall responsibility to review, update, implement, and provide support through policies and procedures that will assist the educator to deter, detect, and deal with this epidemic in a safe and forthright manner.

One way of identifying plagiarism in distance education is with and through the use of electronic detection programs. Presently, the most frequently used software to detect academic dishonesty in distance education is Turnitin [16-18]. It certainly is not the only software available and does have competition with other commercial software such as My Drop Box, EVE, WcopyFind and Word-CHECK [18]. It is not the name of the software that is important but it is the availability of the software of choice, and even more important the support that is offered to the educator from university administration once plagiarism has been detected.

In order for an educator to have this detection software obtainable for use it must first be approved and purchased through administration. The use of Turnitin or most other detection software products is not cheap and the cost can sometimes be a deterrent to administration. Some anti-plagiarism software requires a subscription and in some instances the costs can increase with the use and number of students involved. The cost of these software detection programs is a necessary factor that is of greater concern to the administration than to the individual educator [17]. Some of the companies offer a free trial, others request flat-rate fees, and still others require fees per submission. For large universities this can be 
costly and for smaller institutions of learning it can be overwhelming. There is no way around the cost issues as the software companies require support for the product and for upgrading and enhancing the service they provide.

A risk to educators stems from the fact that administration must continue to enforce the use of this product with consistency and follow-thru when plagiarism is detected [19]. Support for the educator, from the university judicial system, is imperative to encourage continued use of anti-plagiarism products. If the process becomes too laborious or is not fully supported through administrative process then it is possible many educators may become reluctant to detect and report plagiarism. Therefore the judicial system in place needs to be simple and supportive. This can be addressed with the use of policies and procedures and follow-through of those policies and procedures by the educator and the administration alike. Well written policies on academic honesty and cheating are vital to assist the educator in appropriate action once they have identified a case of plagiarism [16].

In addition to the policies it is imperative administration is ready to consistently support faculty members with follow-thru in cases where academic dishonesty had been detected. Without that support the educator may fear retaliation or even litigation. Some educators may even fear being reprimanded by administration and/or students and the student's family members. Their teaching pedagogy, their grading policies and even their online methods of accepting assignments and student papers can be questioned [19]. If this is the case then the educator may refrain from reporting suspected cheating.

A good definition of what constitutes plagiarism is first and foremost prior to writing applicable policies and procedures that address the desired factors [20]. Once this has been accomplished the administration can more readily identify the policies and procedures that apply to their specific definition. The faculty and the student can then use this definition to determine and implement academic integrity as defined by the administration. This process will help the university to define what they consider a violation of academic integrity and will then give a solid foundation for the educator to work from. This can also address the implementation of appropriate teaching techniques, honest grading policies, and online and distance education integrity to help the educator feel more comfortable in reporting and dealing with cheating [20].

\section{PREVENTION TECHNIQUES- EDUCATOR}

Administration plays an important role in preventing plagiarism in Web-enhanced education but equally im- portant is the role of the nurse educator. Many of our present day educators are involved in teaching wholly or partially online. Those that do teach through the Web will usually educate their students with the use of a variety of activities found on the Internet. The Internet also becomes the main source, and in some instances the only source of sending and receiving information. Educators in this setting are usually very aware of the practice of plagiarism by the students [12,22]. Students in the online environment use the plethora of information that is readily available online. It is considered a reputable resource for research, yet many educators look upon the Internet as one of the problems in how students perceive and interact with academic honesty. Many educators may see the Internet as the perpetrator when it comes to online plagiarism [12]. Educators are frequently presented with papers and group work that has been copied or "cut and pasted" into a document without the appropriate referencing or paraphrasing required.

There is little doubt that educators in every setting, but especially in the web-enhanced setting know and understand plagiarism and how it works. It is how they approach the problem that will often differ. There may be no one "right" approach that will obliterate plagiarism in its entirety, especially in distance learning. There are however, a couple of approaches that are presently being used to discourage online students from participating in these dishonest behaviors. One strategy is to use electronic software such as the previously mentioned Turnitin. The other strategy is to assume much of the illegal use is produced through ignorance and that increased knowledge and education for the students will help to prevent the frequency and violation of illegal use. Most online educators will use one of these strategies and some will use both approaches to cut down on academic dishonesty.

Ledwith and Risquez (2008) completed a study to determine if the use of anti-plagiarism software really did promote academic honesty. They reported a considerable decrease in Internet plagiarism with the use of Turnitin. Furthermore they reported that the students who participated in the study indicated that with the use of Turnitin they were able to increase their knowledge and awareness of plagiarism, which in turn decreased honest mistakes made through ignorance. On the other hand they pointed out the results of this study did not indicate that "academic integrity values were developed in the process" (p. 382). This is an important factor to identify as it does not mislead the educator to believe, once ignorance of plagiarism has been overcome, it will be avoided at all costs. Research and statistics continue to support the reality that high percentages of college students have cheated or plagiarized at least one or more times throughout their college education. College students will 
readily admit to cheating when they are asked for anonymous voluntary admission of plagiarism [4]. This can create a problem for the educator.

When making the decision to use anti-plagiarism software there are best-practice suggestions for the educator [18]. These suggestions are offered to help the educator implement this tool in a way that will help the students see it as a constructive and accommodating tool rather than as a method of educator control. Those suggestions include: notifying the students of the software to be used and doing so in advance of the semester, providing training on the program of choice, communicating and abiding by the academic policy created by the university administration and lastly, allowing the student to resubmit papers that were returned with a high percentage of matching.

Batane (2010) also completed a recent study on the use of Turnitin. The results of this study were very similar to those of Ledwith and Risquez (2008). Decrease in plagiarism with the use of Turnitin was found in Batane's study as well. However, Batane concluded that while the use of anti-plagiarism software was effective it was not as effective as using this approach with a more interactive and comprehensive pedagogical approach. Batane identified the importance of the university to determine a way to educate students on the importance of obtaining their degree honorably. Many agree with this approach and would even suggest that student education on plagiarism is a better way to help the student avoid common errors [12,15,21,22].

\section{EDUCATING THE STUDENT}

Many of our present day students do not have enough information on what plagiarism consists of. A better way of helping students avoid plagiarism might be to educate them on the definitions, the policies, and the consequences of cheating. The more knowledge the students have the easier it would be for the educator to enforce appropriate consequences should plagiarism occur [21]. This may be a much better approach to plagiarism than the use of anti-plagiarism software. Educating students on what plagiarism consists of and how to avoid plagiarism has some advantages. Directing the student to use university resources or student services that offer to review student coursework prior to submission could prove to be more productive for the educator and the student [12]. The student can then receive valuable feedback from professionals prior to submitting the assignment.

The Internet may not be the culprit [22]. In Bokan's (2006) discussion on ways to detect and prevent plagiarism he stated "the Internet certainly enables more efficient plagiarism”, however "blaming it for wide spread copying is akin to blaming a bank robbery on the pres- ence of cash in the building” (p. 10). His meaning is clear. Just because the Internet is there does not indicate everyone that enters intends to rob it. He admitted that a great many students are now practicing plagiarism but determined the greater percentage just lack the knowledge of what that entails. He suggested the educator should make it common practice to teach the student what plagiarism is and is not, but should also look at what and how they require assignments to be completed. One strategy he mentions is the need for the educator to employ solid assessment and good teaching into their classroom environment.

The Internet may not be the perpetrator for plagiarism but it is certainly one of the dynamics that make it easier for the student to participate in plagiarism [12]. Howard and Davies, 2006, suggested four strategies to assist the educator in the online setting. Those strategies include: creating an open discussion on the definition of intellectual property; assisting the student to make comparisons of online reliability; guiding the student in understanding how to reference sources; and maintaining contact and good teaching techniques and responses throughout the course.

In most instances students just need to understand the online pedagogy [12]. Pedagogy in the online setting sometimes turns the students loose to read and write and report. When they commit plagiarism, whether it be purposefully or out of ignorance, the educator is usually surprised and offended. Pedagogy and teaching that includes social, ethical, and human issues will help students avoid plagiarism and educators avoid the surprise of plagiarism. Increasing student knowledge and understanding in issues related to technology and responsible use of the Internet is an important part of that pedagogy [22].

\section{SUMMARY}

There is no doubt that one of the significant differences of distance education from traditional education is the physical disconnection. This should not be taken away from the education that the educator facilitates or the student receives. There are, however, some ethical considerations in distance education which may be increased due to this geographical separation. The most blatant consideration is that of academic honesty and plagiarism. Neither faculty nor administration can obliterate plagiarism, but each can implement strategies which will help decrease this growing practice. Administrators can purchase and implement anti-plagiarism software which will assist the educator to more easily detect plagiarism. In addition, they can define what plagiarism means to their institution and put policies and procedures in place which will help deter, detect, and deal with plagiarism 
[16]. Once the policies have been identified and implemented, administration has the responsibility to support the educator when plagiarism has been identified.

The educator has a much more interactive role in deterring, detecting, and dealing with plagiarism. The educator can use the anti-plagiarism software provided by the university, but it must also include a pedagogical approach to deter and deal with plagiarism. The Internet has brought a great deal of new and wonderful information to our world. It has made access to the information extremely fast and readily available. It can be a good thing and it can add a great deal of knowledge to any educational endeavor. Sadly, there is no hope that plagiarism will be completely eliminated with either strategy. The best solution to address plagiarism in distant learning at the present time may be a combination of using both strategies.

\section{REFERENCES}

[1] Jones, L.R. (2011) Academic dishonesty: Are more students cheating? Business Communication Quarterly, 74, 141-150. http://dx.doi.org/10.1177/1080569911404059

[2] Hall, S.E. (2011) Is it happening? How to avoid the deleterious effects of plagiarism and cheating in your courses. Business Communication Quarterly, 74, 179-182. http://dx.doi.org/10.1177/1080569911404057

[3] Wideman, M. (2011) Caring or collusion? Academic dishonesty in a school of nursing. Canadian Journal of Higher Education, 41, 28-43.

[4] Austin, Z., Simpson, S. and Reynen, E. (2005) The fault lies not in our students, but in ourselves: Academic honesty and moral development in health professions education-Results of a pilot study in Canadian pharmacy. Teaching in Higher Education, 10, 143-156. http://dx.doi.org/10.1080/1356251042000337918

[5] Power, L.G. (2009) University students' perception of plagiarism. The Journal of Higher Education, 80, 643662. http://dx.doi.org/10.1353/jhe.0.0073

[6] (2011) Quality and safety education for nurses. Quality and safety competencies. http://www.QSEN.org/competencies.php

[7] Robinia, K.A. and Anderson, M.L. (2010) Online teaching efficacy of nurse faculty. Journal of Professional Nursing, 26, 168-175. http://dx.doi.org/10.1016/j.profnurs.2010.02.006

[8] Cronenwett, L., Sherwood, G. and Gelmon, S.B. (2009) Improving quality and safety education: The QSEN learning collaborative. Nursing Outlook, 57, 304-312. http://dx.doi.org/10.1016/j.outlook.2009.09.004

[9] Wilson, B.G. (2004) Designing e-learning environments for flexible activity and instruction. Educational Tech- nology Research and Development, 52, 77-84. http://dx.doi.org/10.1007/BF02504720

[10] Enlow, M, Shanks, L., Guhde, J. and Perkins, M. (2010) Incorporating interprofessional communication skills (ISBARR) into an undergraduate nursing curriculum. Nurse Educator, 35, 176-180. http://dx.doi.org/10.1097/NNE.0b013e3181e339ac

[11] Taylor, L.A., Hudson, K., Vazzano, J., Naumann, P. and Neal, M. (2010) The electronic health record meets baccalaureate nursing curriculum: Stories from the battlefield. Nurse Leader, 8, 40-44. http://dx.doi.org/10.1016/j.mnl.2010.03.008

[12] Howard, R.M. and Davis, L.J. (2009) Plagiarism in the internet age. Educational Leadership, 66, 64-67.

[13] Baggaley, J. and Spencer, B. (2005) The mind of a plagiarist. Learning Media and Technology, 30, 55-62. http://dx.doi.org/10.1080/13581650500075587

[14] Sikes, P. (2009) Will the real author come forward? Questions of ethics, plagiarism, theft and collision in academic research writing. International Journal of Research \& Method in Education, 32, 13-24. http://dx.doi.org/10.1080/17437270902749247

[15] Nealy, C. (2011) Rethinking plagiarism. Business Communication Quarterly, 74, 205-209. http://dx.doi.org/10.1177/1080569911404056

[16] Bretag, T. and Mahmud, S. (2009) A model for determining student plagiarism: Electronic detection and academic judgment. Journal of University Teaching and Learning Practice, 6, Article 6.

[17] McKeever, L. (2006) Online plagiarism detection services-Savior or scourge? Assessment \& Evaluation in Higher Education, 31, 155-165. http://dx.doi.org/10.1080/02602930500262460

[18] Ledwith, A. and Risquez, A. (2008) Using anti-plagiarism software to promote academic honesty in the context of peer reviewed assignments. Studies in Higher Education, 33, 371-384. http://dx.doi.org/10.1080/03075070802211562

[19] Chao, C., Wilhelm, W.J. and Neureuther, B.D. (2009) A study of electronic detection and pedagogical approaches for reducing plagiarism. The Delta Pi Epsilon Journal, 51, 31-42.

[20] Price, M. (2002) Beyond “gotcha!” Situating plagiarism in policy and pedagogy. College Composition and Communication, 54, 88-115. http://dx.doi.org/10.2307/1512103

[21] Belter, R.W. and duPre, A. (2009) A strategy to reduce plagiarism in an undergraduate course. Teaching of Psychology, 36, 257-261. http://dx.doi.org/10.1080/00986280903173165

[22] Bolkan, J.V. (2006) Avoid the plague: Tips and tricks for preventing and detecting plagiarism. Learning \& Leading with Technology, 33, 10-13. 